\title{
No superior treatment for primary osteochondral defects of the talus
}

\author{
Jari Dahmen ${ }^{1,2,3}$ - Kaj T. A. Lambers ${ }^{1,2,3}$ - Mikel L. Reilingh ${ }^{1,2,3}$ - Christiaan J. A. van Bergen ${ }^{1,2,3,4}$. \\ Sjoerd. A. S. Stufkens ${ }^{1,2,3} \cdot$ Gino M. M. J. Kerkhoffs ${ }^{1,2,3}$
}

Received: 13 February 2017 / Accepted: 19 June 2017 / Published online: 27 June 2017

(C) The Author(s) 2017. This article is an open access publication

\begin{abstract}
Purpose The purpose of this systematic literature review is to detect the most effective treatment option for primary talar osteochondral defects in adults.

Methods A literature search was performed to identify studies published from January 1996 to February 2017 using PubMed (MEDLINE), EMBASE, CDSR, DARE, and CENTRAL. Two authors separately and independently screened the search results and conducted the quality assessment using the Newcastle-Ottawa Scale. Subsequently, success rates per separate study were calculated. Studies methodologically eligible for a simplified pooling method were combined.

Results Fifty-two studies with 1236 primary talar osteochondral defects were included of which forty-one studies were retrospective and eleven prospective. Two randomised controlled trials (RCTs) were identified. Heterogeneity concerning methodological nature was observed, and there was variety in reported success rates. A simplified pooling
\end{abstract}

Jari Dahmen and Kaj T. A. Lambers both contributed equally to this work and thus share first authorship.

Gino M. M. J. Kerkhoffs

g.m.kerkhoffs@amc.uva.nl; g.m.kerkhoffs@amc.nl

1 Department of Orthopedic Surgery, Academic Medical Centre, University of Amsterdam, Meibergdreef 9, 1105 AZ Amsterdam, The Netherlands

2 Academic Center for Evidence based Sports medicine (ACES), Meibergdreef 9, 1105 AZ Amsterdam, The Netherlands

3 Amsterdam Collaboration for Health and Safety in Sports (ACHSS), AMC/VUmc IOC Research Center, Meibergdreef 9, 1105 AZ Amsterdam, The Netherlands

4 Department of Orthopedic Surgery, Amphia Hospital, Breda, The Netherlands method performed for eleven retrospective case series including 317 ankles in the bone marrow stimulation group yielded a success rate of $82 \%$ [CI 78-86\%]. For seven retrospective case series investigating an osteochondral autograft transfer system or an osteoperiosteal cylinder graft insertion with in total 78 included ankles the pooled success rate was calculated to be $77 \%$ [CI 66-85\%].

Conclusions For primary talar osteochondral defects, none of the treatment options showed any superiority over others.

Level of evidence IV.

Keywords Ankle - Talus - Osteochondral lesion - Defect · Systematic review $\cdot$ Arthroscopy $\cdot$ Articular cartilage $\cdot$

Success rate

\section{Introduction}

A talar osteochondral defect (OCD) is a combined lesion of the subchondral bone and its overlying cartilage and often has a severe impact on the quality of life of active patients [134]. The general consensus is that bone marrow stimulation (BMS) is administered for primary smaller defects. Other surgical options are internal fixation, osteochondral autograft transfer systems (OATS), chondrocyte implantation, retrograde drilling, metal resurfacing, total ankle prostheses or arthrodesis [44, 56, 124].

The effectiveness of the interventions varies greatly in the literature, and although a number of previous systematic reviews have been conducted, a definite treatment option regarded as the golden standard has yet to be identified $[32,69,85,119,128,135]$. Additionally, prior systematic reviews either investigated sole treatment options or did not distinguish between primary and non-primary talar 
defects $[32,69,85,135]$. Therefore, this could introduce a mispresentation of the reported success rates. Furthermore, the most comprehensive review by Zengerink et al. [135] included articles published up to 2006. Since then, a high number of articles investigating novel interventions for talar OCDs have been published [66, 94, 95, 122]. The aim of the present review is therefore to examine and compare the clinical effectiveness of all treatment strategies for exclusively primary talar OCDs in adults. The hypothesis is that no significant differences considering clinical outcome of these different treatment strategies are to be found. This study presents novel findings and gives novel insight into the clinical effectiveness of treatment strategies for primary talar osteochondral defects exclusively.

\section{Materials and methods}

The systematic review was prospectively registered at the PROSPERO register [23].

\section{Search strategy}

Electronic databases PubMed (MEDLINE), EMBASE, CDSR, DARE and CENTRAL were screened from January 1996 to February 2017 for potential suitable articles (Appendix 1). This time frame was chosen as by 1996 the arthroscopic techniques for treating talar OCDs were fully developed and established in the orthopaedic field [126].
The full search strategy for all electronic databases is outlined in Appendix 1. Backward citation chaining strategy was applied as an additional search technique.

\section{Eligibility criteria and study selection (Fig. 1)}

Suitable randomised controlled trials (RCT) and observational studies assessing the effectiveness of all treatment strategies for primary talar OCDs in the adult patient population were included in the present study. The rationale for including non-randomised clinical studies is based on the substantial presence of the low-quality evidence research into talar osteochondral defects that has been conducted over the past two decades. The exclusion criteria for our review are presented in Table 1 . When necessary, authors were contacted to provide separate data for patients with primary lesions only and/or for patients $\geq 18$ years old. When no reply was reported, contact was sought by two reminder e-mails. If no response was recorded, the specific article was excluded. Independent evaluation of the articles and a subsequent discussion were performed by two reviewers (J.D. and K.L.) after title, abstract screening and full-text reading. In case of any disagreement after discussion, the opinion from an independent third investigator (G.K.) was decisive. Studies were not blinded for author, affiliation or source, and no limitations were put on language and publication status. The literature selection algorithm according to the preferred reporting items for systematic reviews and meta-analyses (PRISMA) is presented in Fig. 1 [67].

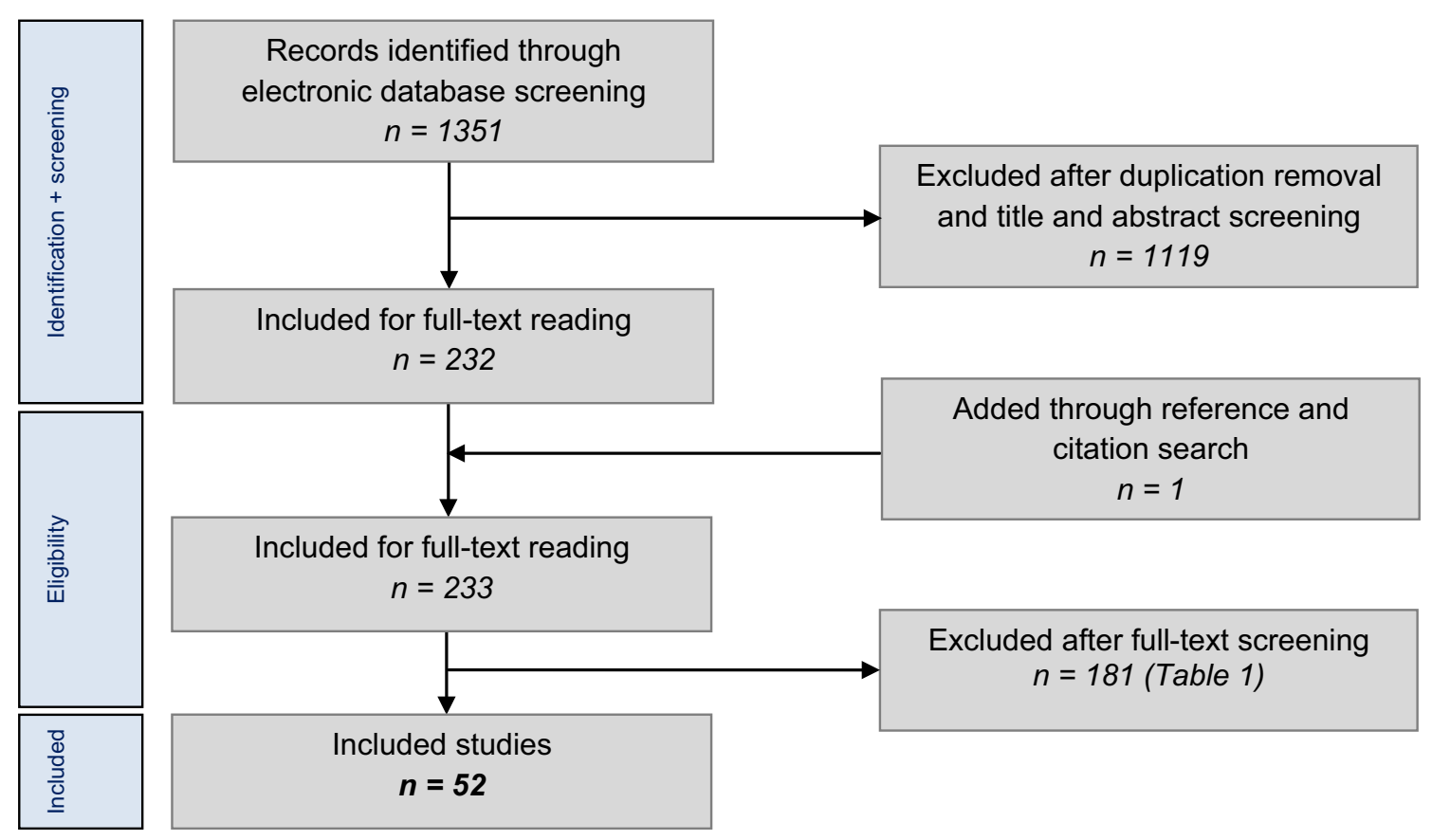

Fig. 1 Literature selection algorithm—-preferred reporting items for systematic reviews and meta-analyses (PRISMA) 
Table 1 Exclusion criteria

\begin{tabular}{lc}
\hline Exclusion criteria & No. of studies \\
\hline Non-primary OCDs & 91 \\
$<5$ patients & 20 \\
Age: $<18$ years old & 17 \\
Patient overlap & 14 \\
Treatment inappropriately described & 13 \\
Combination of diagnoses (bipolar, fracture, etc.) & 13 \\
Combination of treatment groups and/or no separate & 8 \\
$\quad$ data per group & 2 \\
Follow-up <6 months & 2 \\
Interpretable data not available & 1 \\
Asymptomatic lesion & 181 \\
Total no. of excluded studies & \\
\hline
\end{tabular}

Some publications were excluded due to a combination of reasons

\section{Critical appraisal}

A for-talar-OCD-modified Newcastle-Ottawa Scale (NOS) was utilised to assess the methodological quality (Appendix 3). Each included study was graded on methodological quality by two independent reviewers (J.D. and K.L.). When there was no agreement on the number of stars graded, assessment by an independent third investigator (G.K.) was decisive.

\section{Data extraction}

By means of a standardised extraction form, data from the articles were extracted on study characteristics. Data on patient characteristics were retrieved and included age, gender, number of patients and ankles, symptom duration, location, side, size and stage of the defect according to a specifically reported OCD classification system, clinical scoring system utilised, history of ankle trauma and follow-up duration. Pre-operative and post-operative clinical outcome scores were extracted on mean scores, subjective satisfaction and number of patients treated successfully. The treatment strategy in question was defined to be successful when a good or excellent result at follow-up was reported, in combination with an accepted scoring system. The results were incorporated into the scoring system of Thompson and Loomer [118] (Appendix 2) when separate patient data were available though no success rates of specific treatment strategies were included. An ankle was considered to be successfully treated when at latest follow-up a post-operative AOFAS score at or above 80 was reached [59]. In case of the FAAM (Foot and Ankle Ability Measure) score, a percentage of 80 or higher was regarded to be a successful treatment [75].

\section{Statistical and data analysis}

In case of identifying studies with highly differing methodological natures, a formal meta-analysis will not be

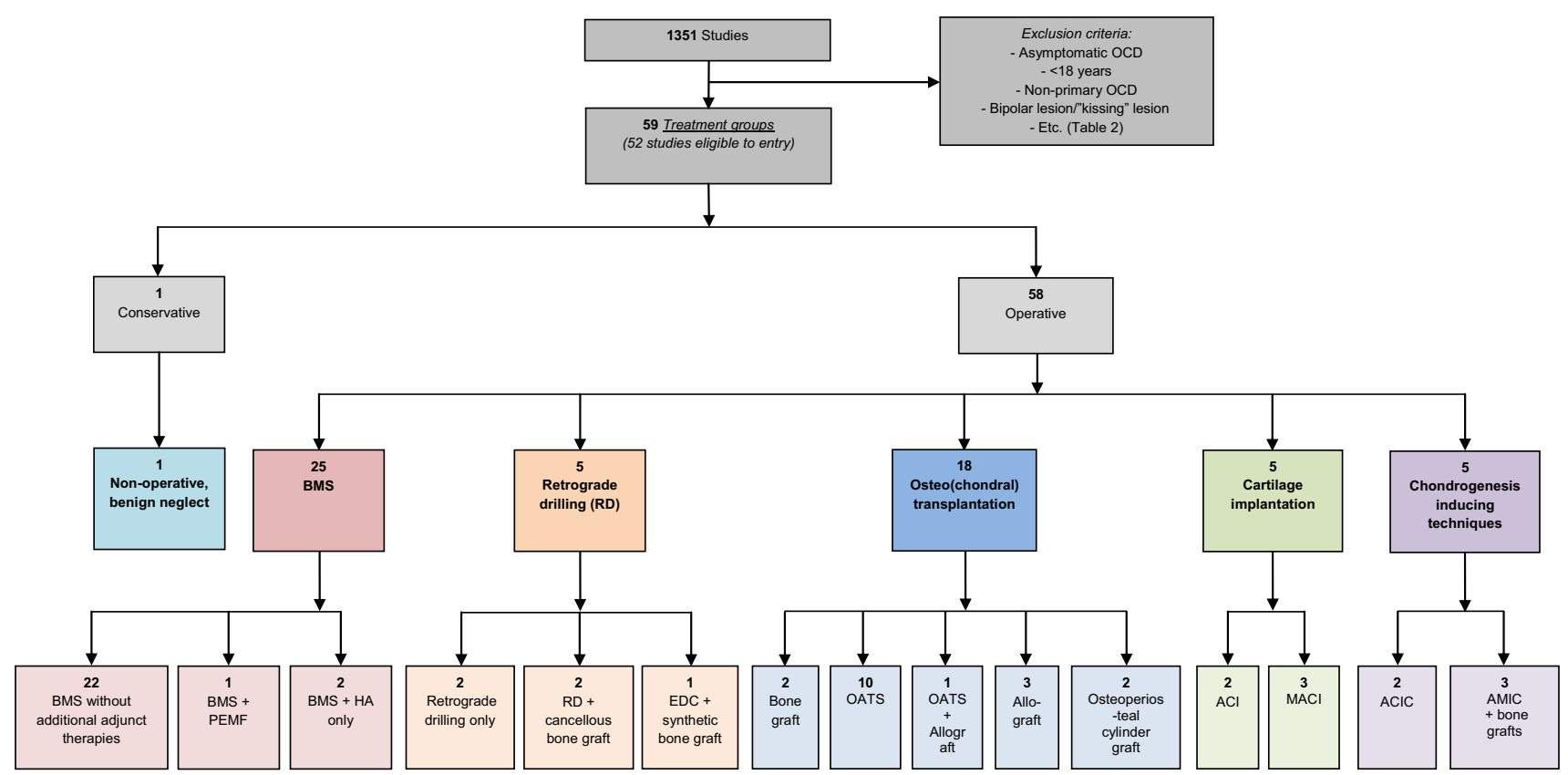

Fig. 2 Flow chart of study inclusion and treatment of talar OCDs between 1996 and 2017. ACI autologous chondrocyte implantation, $A C I C$ autologous collagen-induced chondrogenesis, AMIC autologous matrix-induced chondrogenesis, $R D$ retrograde drilling, $B M S$ bone marrow stimulation, MACI matrix-associated chondrocyte implantation, OATS osteochondral autograft transfer system, HA hyaluronic acid, PEMF pulsed electromagnetic fields, $E C D$ endoscopic core decompression 
Table 2 Clinical scoring systems utilised for treatment of talar OCDs and associated knee scores in case of implantation techniques

\begin{tabular}{ll}
\hline Clinical scoring system & No. of studies \\
\hline AOFAS Ankle/Hindfoot Scale [59] & 43 \\
VAS (Visual Analog Scale) [21] & 27 \\
Patient Satisfaction Score & 17 \\
Tegner score [116] & 3 \\
Short Form-36 [131] & 4 \\
Hannover score [117] & 3 \\
Freiburg Ankle Score [62] & 3 \\
Criteria proposed by Berndt and Harty [15] & 3 \\
Ogilvie Harris Score [90] & 3 \\
Ankle Activity Score [48] & 2 \\
Modified Cincinnati Knee Rating System [35] & 2 \\
Hospital of Special Surgery Patella Score [9] & 2 \\
IKDC Subjective and Objective Knee Evaluation & 2 \\
Form [51, 86] & 1 \\
Clinical evaluation proposed by Shearer and Loomer & 1 \\
[109] & 1 \\
RTA (Return to Activity) [105] & 1 \\
NRS (Numeric Rating Scale for pain and satisfaction) & 1 \\
[39, 100] & 1 \\
Saxena criteria [105] & 1 \\
FAAM (Foot and Ankle Ability Measure) [75] & 1 \\
McCullough Score [76] & 1 \\
Foot Functioning Index [83] & 1 \\
MODEMS AAOS Foot and Ankle Follow-up Ques- & 1 \\
tionnaire [82] & \\
Modified Cincinnati Knee Documentation Rating [72] & 1 \\
Bandi Knee Global Assessment Score [10] & 1 \\
Lysholm [71] & 1 \\
Foot and Ankle Disability Index (FADI) [49] & 1 \\
\hline
\end{tabular}

Some studies utilised $>1$ scoring system

performed. It will be decided upon visualising the results per study by means of a forest plot. If possible, a simplified pooling method will be used to combine data from different studies describing the results of similar treatment groups research by means of analogous methodologies. 95\% binomial proportion confidence intervals for the success percentages of each study and the pooled studies will be calculated with the Wilson score interval and included in the forest plots (CIA, Confidence Interval Analysis for Windows, version 2.2.0) [19].

\section{Results}

\section{Search results}

The literature search yielded 1351 articles, and after title and abstract screening, 232 potentially suitable articles
Table 3 Classification systems utilised for osteochondral damage staging assessment

\begin{tabular}{ll}
\hline Classification systems & No. of studies \\
\hline Berndt and Harty Classification System [15] & 16 \\
MOCART [73] & 8 \\
International Cartilage Repair Society (ICRS) [18] & 8 \\
Hepple et al. [52] & 5 \\
Ferkel and Cheng [37] & 3 \\
Anderson et al. [6] & 3 \\
Dipaola et al. [30] & 3 \\
Outerbridge Classification System [87] & 2 \\
Bristol Classification System [101] & 2 \\
Osteoarthritis Classification System [125] & 1 \\
Sefton Articular Stability Scale [107] & 1 \\
Pritsch Classification System [97] & 1 \\
FOC (Fracture, Osteonecrosis, Cyst) [34] & 1 \\
Takakura Radiologic Arthrosis Classification System & 1 \\
[113] & \\
Giannini Classification System [42] & 1 \\
Scranton and McDermott Classification System [106] & 1 \\
Mintz et al. [79] & 1 \\
Guhl [46] & 1 \\
\hline
\end{tabular}

Some studies utilised $>1$ classification system, and others did not utilise a classification system

were included for full-text reading (Fig. 2). One study was added through reference and citation search. In total, 127 authors were contacted to request data according to our inclusion criteria. Subsequently, 33 studies could be included and 31 had to be excluded attributable to the extensive author contact process. In total, 181 publications had to be excluded due to a variety and combination of reasons (Table 1). This left 52 studies in total.

After screening and discussion between the first two authors there was overall consensus in all cases except for four where disagreement persisted. These were resolved by discussion with the senior author (G.K.).

Full consensus was reached between the reviewers regarding grading of methodological quality.

\section{Evaluation of the characteristics of included studies}

A total of 1236 primary talar OCDs were included in the 52 studies. The average age was 36 [range 18-77], and the percentage of females and males was 34 and $66 \%$, respectively. The right ankle was involved in $54 \%$ of the cases and the left ankle in $46 \%$. The percentages of medial, lateral, central and combined medial and lateral location involvement were $77,21,2$ and $0.4 \%$, respectively. In $71 \%$ of the patients, a history of ankle trauma was reported. The most frequently used clinical scoring system and osteochondral 
Table 4 Table presenting the separate results of the adjusted Newcastle-Ottawa Scale

\begin{tabular}{lccl}
\hline Category in question & Number of stars & Maximum number of stars & Proportion \\
\hline Study design & 65 & 104 & $65 / 104=63 \%$ \\
Selection & 43 & 52 & $43 / 52=83 \%$ \\
Outcome & 104 & $74 / 104=71 \%$ \\
Total & 74 & 260 & $182 / 260=70 \%$ \\
\hline
\end{tabular}

damage classification system were the AOFAS and the Berndt and Harty Classification system, respectively [15, 59]. In total 25 different types of clinical scoring systems (Table 2) [9, 10, 15, 21, 35, 39, 48, 51, 59, 62, 71, 72, 75, $76,82,83,86,90,100,105,109,116,117,131]$ and 18 different utilised osteochondral damage classification systems were found (Table 3) [6, 15, 18, 30, 34, 37, 42, 46, 52, $73,79,87,97,106,107,125]$. Data were extracted on the combined Berndt and Harty [15] and Loomer [68] stages for 257 ankles: there were 56 (22\%), 68 (27\%), 70 (27\%), $37(14 \%)$ and $26(10 \%)$ Berndt and Harty [15] stage I, II, III, IV and V cases, respectively. Lastly, the mean of the follow-up time ranged from 6 to 143 months.

\section{Methodological quality}

The fifty-two publications altogether scored 182 stars out of maximum 260 stars (Table 4). Forty-one studies were assessed to be retrospectively conducted, and all studies except for two were conducted according to the study protocol. Therefore, all studies together scored a total number of 65 stars $(\max .=104)$ on study design. Regarding the selection procedure, 43 out of 52 stars were scored in total, indicating that most studies reported a representative talar OCD patient population. Seventy-four out of 104 stars were scored on the outcome part of the adjusted Newcastle-Ottawa Scale. Independent blind assessment was performed in none of the studies, and in all except for one study outcome was assessed through record linkage. Numerical star outcomes on adequacy of follow-up of series were not uniform across the included studies.

\section{Treatment strategies}

The different treatment strategies were divided into six corresponding treatment groups. It was deemed methodologically appropriate to perform a simplified pooling method for the largest groups of those publications with corresponding methodological nature (i.e. retrospective case series together) in the groups of BMS and osteo(chondral) transplantation-more specifically OATS and an osteoperiosteal cylinder graft insertion. No studies describing a mosaicplasty procedure were included in this pooling group as mosaicplasty uses multiple graft insertion procedures applied for the treatment of larger talar defects which is in contrast to the classic OATS procedure. Consequently, pooling the mosaicplasty studies was not appropriate. The forest plot describing the clinical results in percentages per separate study in their corresponding treatment group is presented in Fig. 3, and the forest plot describing the results of the simplified pooling method is presented in Fig. 4.

\section{Non-operative}

The objective of non-operative treatment is to unload the damaged cartilage potentially resolving accumulated oedema within the joint.

One retrospective case series study investigated solely chronic-type $\mathrm{V}$ cystic lesions as classified by Loomer et al. [68, 109]. Non-operative treatment consisted of continuation of activities "as tolerated" [109]. Mean symptom duration, mean follow-up, patient satisfaction scores and preoperative OCD size could not be recorded. Eventually, in 16 out of 26 patients conservative treatment yielded successful results, which corresponded to a success rate of 62\% [CI 43-78\%] (Fig. 3) [109].

\section{Bone marrow stimulation (debridement and/or drilling)}

BMS consists of debriding the OCD after which additional microfracturing or antegrade drilling can be performed establishing openings into the subchondral bone. This disrupts intraosseous vessels introducing blood and bone marrow cells into the OCD allowing a clot of scar tissue to form resulting in fibrocartilaginous tissue. Supplementary, one can administer hyaluronic acid (HA) injections acting as a synovial lubricator targeting pain levels and inflammatory cytokine concentrations [81, 112]. Another possibility is the use of pulsed electromagnetic fields (PEMF) [1, 17, 26, 91, 103, 129].

Twenty-two studies describing the results of BMS for 747 ankles were identified [8, 11, 24, 27, 31, 33, 45, 55, 61, 65, 77, 78, 93, 96, 100, 104, 105, 108, 114, 115, 123, 133]. There were two RCTs, two prospective cohort studies and one retrospective cohort study, three prospective case series, three retrospective comparative studies and eleven retrospective case series. This shows the great 


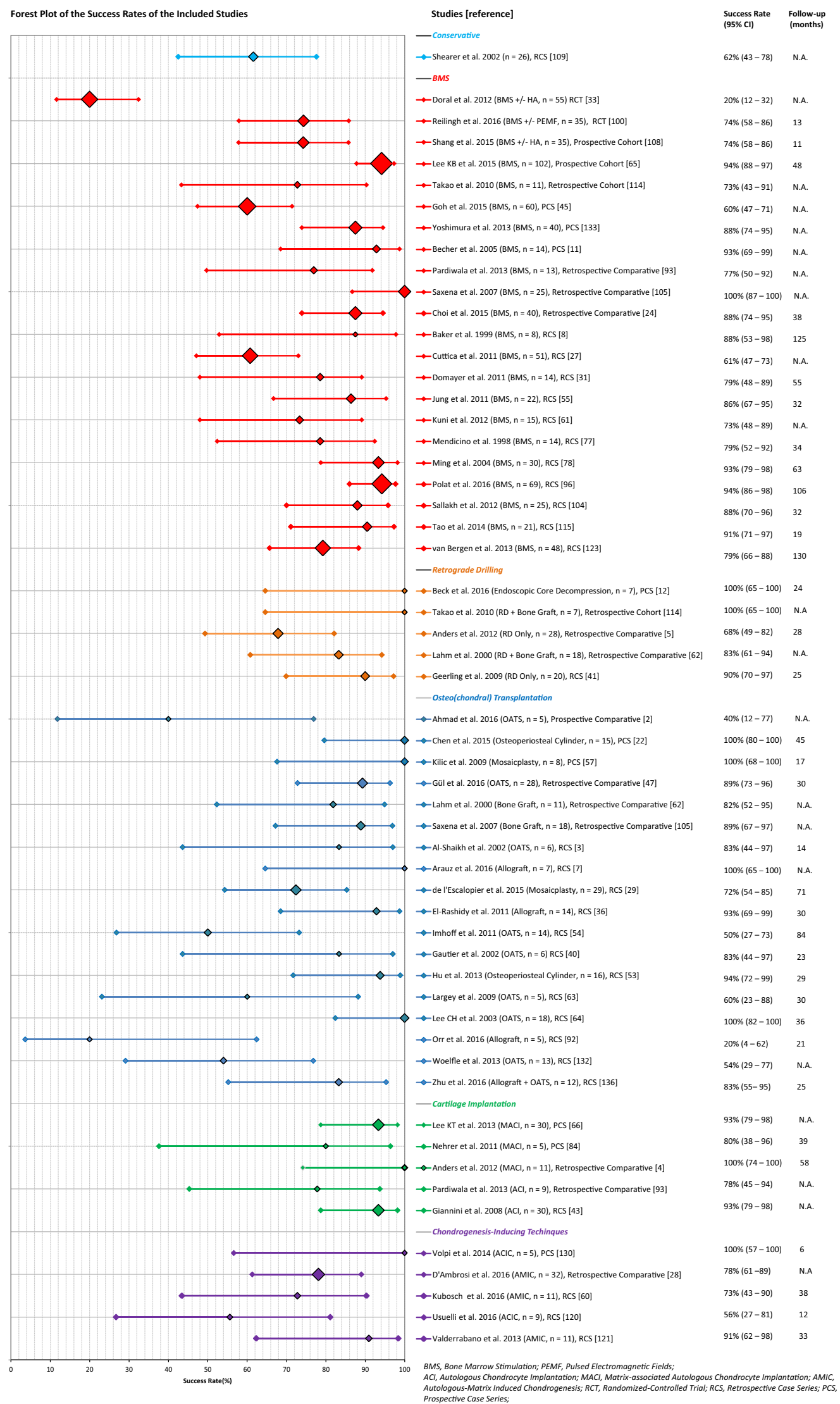


4Fig. 3 Forest plot of all included studies with the success rates and the corresponding $95 \%$ confidence interval per separate study (sorted on treatment strategy group, methodological quality and alphabetical order accompanied by number of ankles and mean follow-up duration; the size of the diamond representing the success rate is adjusted for the number of ankles included in the publications)

heterogeneity in methodological nature of the studies within this group. The means of the symptom duration of these studies ranged from 4 to 49 months, and the range of the means of the follow-up duration in months was as follows: 10-143 months (Fig. 3). For 194 ankles data on Berndt and Harty [15] staging could be extracted: 23, 31, 33 and $13 \%$ were affected by stage I, II, III and IV lesions, respectively $[8,24,65,78]$. The means of the pre-operative size of the talar OCD ranged from 1.0 to $1.7 \mathrm{~cm}^{2}[24,65$, $96,105,108,115]$. The success percentages of the separate studies corresponding to the BMS group ranged from 20 to 100\% [CI 12-100\%] (Fig. 3) [8, 11, 24, 27, 31, 33, 45, 55, 61, 65, 77, 78, 93, 96, 100, 104, 105, 108, 114, 115, 123, 133]. There were eleven studies within the BMS group that all investigated the patients in a retrospective case series setting, making it methodologically appropriate to perform a simplified pooling method for this subgroup [8, 27, 31, $55,61,77,78,96,104,115,123]$. It contained 317 talar OCDs yielding a pooled success rate of $82 \%$ [CI 78-86\%] (Fig. 4).

\section{Retrograde drilling}

Retrograde drilling (RD) is a non-transarticular procedure preventing injury to the articular cartilage. Consequently, the technique is primarily used when defects contain a relatively small amount of articular cartilage damage or when it is challenging to reach the OCD via the common arthroscopic portals. The aim is to revascularise the subchondral bone and induce novel bone formation. Additional procedures one can administer are cancellous bone grafts.

Five studies with a total of 80 ankles having undergone retrograde drilling were identified [5, 12, 41, 62, 114]. One prospective case series, one retrospective cohort study, one retrospective case series and two retrospective comparative studies were identified. Therefore, due to the heterogeneity this did not allow for pooling. Furthermore, concerning symptom duration, Berndt and Harty [15] staging and sizes of the talar OCDs, there was insufficient information to provide data on ranges of means reported in the cited literature. The range of the means of follow-up duration was 24-28 months (Fig. 3). The success percentages in this treatment group ranged from 68 to $100 \%$ [CI 49-100\%] (Fig. 3) [5, 12, 41, 62, 114]. Included in this range were two studies that implemented cancellous bone grafting additional to retrograde drilling with mean success rates ranging from 83 to $100 \%$ [CI 61-100\%] and two studies that performed retrograde drilling (range 68-90\%, CI 49-97\%, Fig. 3) [5, 41, 62, 114]. One study by Beck et al. [12] investigated a transtalar endoscopic core decompression combined with the injection of synthetic osteoconductive bone graft substitute. It included 7 patients and yielded a success rate of $100 \%$ (Fig. 3) [CI 65-100\%].

\section{Osteo(chondral) transplantation}

A number of osteo(chondral) transplantation techniques exist to treat talar OCDs: osteochondral autograft transfer systems (OATS), mosaicplasty, (autogenous) bone grafting, autologous osteoperiosteal cylinder grafting and an osteochondral allograft transfer. The procedures consist of debriding the degenerated cartilage, the fibrous tissue and the necrotic subchondral bone, after which the osteo(chondral) grafts are harvested and subsequently implemented into the remaining OCD. The aim is to achieve a higher-quality restoration of the functional unit of the subchondral bone plate including the articular cartilage.

Eighteen studies were identified, which included a total of 230 primary OCDs [2, 3, 7, 22, 29, 36, 40, 47, 53, 54, 57, 62-64, 92, 105, 132, 136]. There were two prospective case series, one prospective comparative study, three retrospective comparative studies and twelve retrospective case series. This did not allow for subsequent overall osteo(chondral) transplantation group pooling. It was not possible to extract sufficient information on the symptom duration, patient subjective satisfaction scores and staging of the defect. The range of the means of the follow-up duration was 14-84 months, and the range of the means of the sizes per particular study 1.0 to $2.4 \mathrm{~cm}^{2}[3,22,36,40$, $47,57,64,92]$. The range of the success percentages per study for the treatment strategy group of osteo(chondral) transplantation was 20 to $100 \%$ [CI 4-100\%] (Fig. 3) [2, 3, 7, 22, 29, 36, 40, 47, 53, 54, 57, 62-64, 92, 105, 132, 136]. The range of the means of the success percentage per separate publication for the OATS group was 40-100\% [CI 12-100\%] (Fig. 3), for the mosaicplasty group 72-100\% [CI 54-100\%] and for one study that combined an OATS and an allograft procedure it was 83\% [CI 55-95\%] (Fig. 3) [2, 3, 29, 40, 47, 54, 57, 63, 64, 132, 136]. After extracting data on donor-site morbidity of 93 primary and secondarily treated talar OCDs by OATS, it became clear that $32 \%$ of the participants showed some form of donor-site knee joint morbidity [2, 3, 29, 40, 63, 64]. Two studies including 31 ankles researched an osteoperiosteal cylinder graft and reported mean success percentages of 94-100\% [CI 72-100\%] (Fig. 3) [22, 53]. Three studies-with in total 19 ankles-investigated the clinical effectiveness of a fresh allograft transplantation, and the success rates ranged from 20 to $100 \%$ [CI 4-100\%] [7, 36, 92]. Additionally, there 


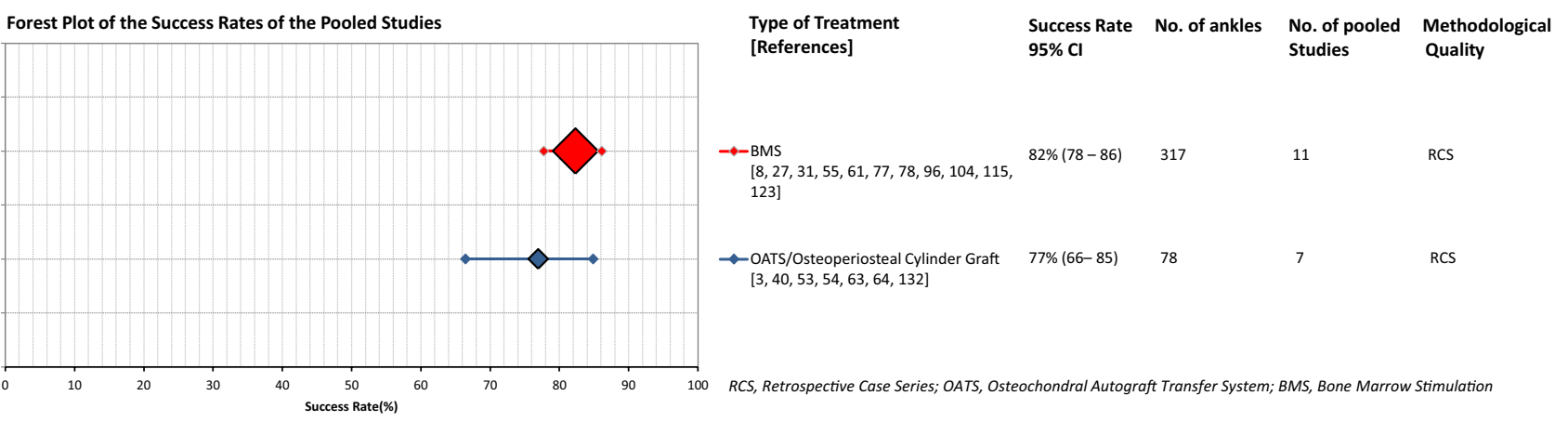

Fig. 4 Forest plot of the pooled success rates of different treatment strategies with the corresponding 95\% confidence intervals (accompanied by the total number of ankles and total number of studies

were two studies performing implementation of cancellous bone grafting into 29 debrided talar OCDs [62, 105]. In this group the success rate ranged from 82 to $89 \%$ [CI 52-97\%] (Fig. 3) [62, 105]. It was possible to perform a simplified pooling method for those studies with a retrospective case series setting investigating an OATS procedure and an osteoperiosteal cylinder graft procedure, and this group of 78 treated talar OCDs yielded a pooled success rate of $77 \%$ [CI 66-85\%] (Fig. 4) [3, 40, 53, 54, 63, 64, 132].

\section{Cartilage implantation}

Cartilage implantation techniques aim at regenerating tissue with hyaline-like type II cartilage. Generally, in twostep procedures viable chondrocytes are isolated from a donor site, after which the chondrocytes are cultivated and expanded in a laboratory medium. The cultured chondrocytes are then implanted into the excised lesion. When applying the ACI procedure, a periosteal tissue cover is used after expansion of isolated chondrocytes, whereas MACI replaces the periosteal cover by a collagen type 1-3 or Hyalograft $\mathrm{C}$ membrane [42]. The latter has the advantage that there is no need for an additional donor site and potentially delivers more viable cells to the OCD [80].

Five studies including 85 ankles investigating cartilage implantation were identified [4, 43, 66, 84, 93]. Two prospective case series, two retrospective comparative studies and one retrospective case series were included in this group. The authors decided not to perform a simplified pooling method. There was insufficient homogeneity and substantial missing data to report mean symptom duration, patient subjective satisfaction scores and staging of the defect. Concerning follow-up duration, it was possible to extract data from two studies, yielding a range of the means of follow-up of 39-58 months (Fig. 3) [4, 84]. From four studies information on talar OCD size could be extracted, included in the pooled group, and the corresponding methodological quality; the size of the diamond representing the pooled success rate is adjusted for the number of ankles included)

which yielded a range of $1.6-1.9 \mathrm{~cm}^{2}[4,43,66,84]$. The success rate ranged from 78 to $100 \%$ [CI 45-100\%] (Fig. 3) $[4,43,66,84,93]$. From these five studies, there were two investigating ACIs $[43,93]$. The range of the success rate was 78-93\% [CI 45-98\%] (Fig. 3) [43, 93]. The other three publications performed a MACI procedure with a total of 46 ankles, and the success percentages ranged from 80 to $100 \%$ [CI 38-100\%] as illustrated in Fig. 3 [4, 66, 84].

\section{Chondrogenesis-inducing techniques (CITs)}

CITs aim at the repair of a bone-cartilage lesion by means of a combined single-step procedure and can be applied for larger, cystic OCDs [13, 14]. The goal is to induce chondrogenesis, and in case of an adjusted autologous matrix-induced chondrogenesis (AMIC) procedure, spongiosa bone-rich in mesenchymal stem cells-is implanted into the defect [20]. Thereafter, an acellular collagen I/III matrix is glued onto the defect. In case of an autologous collagen-induced chondrogenesis (ACIC) procedure, the debrided defect is filled with a mixture of synthetic fibrin glue and collagen gel-based matrix.

Five publications describing the results of 68 ankles treated by CIT were identified [28, 60, 120, 121, 130]. One study was a prospective case series, one was a retrospective comparative study, and the other three were retrospective case series, which discouraged pooling. There was no sufficient data to allow a presentation of the symptom duration, patient subjective satisfaction scores, staging and sizes of the defect. The range of the means of follow-up duration was 6-38 months (Fig. 3). The range of the success rate was $56-100 \%$ [CI 27-100\%] (Fig. 3) [28, 60, 120, $121,130]$. For the AMIC procedures, the range of success percentages was 73 to $91 \%$ [CI 43-98\%] (Fig. 3) [28, 60, 121]. Volpi et al. [130] and Usuelli et al. [120] described the results of ACIC, and the means of the success rate ranged from 56 to $100 \%$ [CI 27-100\%] (Fig. 3). 


\section{Discussion}

To the best of our knowledge, this is the first systematic review investigating the effectiveness of all treatment options for solely primary talar OCDs in adults. The most important finding of the present study is that although aiming at the application of the most appropriate and complete methodology, none of the interventions showed any definite clinical superiority over the others. This was caused by the observed heterogeneity in methodological nature of the studies and the variety in success rates, both intra-treatment strategy group-wise and inter-treatment strategy groupwise. Additionally, performing a simplified pooling method for retrospective case series studies in the BMS group and in the osteo(chondral) transplantation group yielded comparable pooled success rates.

The main finding is partially in contrast to the one derived from the research by Zengerink et al. [135] which concluded that BMS is the most effective treatment strategy for talar OCDs. This systematic review from 2010, however, included both primary and non-primary talar OCDs, which potentially affected the results and the conclusions based on them. It should be acknowledged that the most important finding of the present study was not a consequence of the methodology, as it aspired to include as many suitable articles as possible by not excluding particular treatment strategies-in contrast to previous reviews [32, 85] — and by adhering to a strict author contact protocol.

BMS was the most studied intervention for primary talar OCDs indicating that it is the most frequently practised treatment option for primary talar OCDs worldwide. This is due to the fact that BMS is a relatively inexpensive intervention compared to implantation techniques, has low morbidity, a quick recovery and a fast return to sports. This was shown by studies conducted by Saxena et al. [105] and Reilingh et al. [100] presenting return to sports times ranging from 15 to 17 weeks. The two most recent systematic reviews on BMS reported success rates of 80 and $86 \%$ [32, 135]. When pooling eleven BMS studies, a pooled success rate of $82 \%$ was calculated [CI 78-86\%] (Fig. 4). As this success rate is comparable to the success rate of the pooled retrospective case series design studies in the osteo(chondral) transplantation group describing the results of OATS and an osteoperiosteal cylinder graft insertion (77\% [CI 66-85\%]), it is difficult to assess which surgical treatment strategy is clinically superior, thereby supporting the most important finding of the present study. Important factors play a vital role in the success of the clinical outcome after BMS. BMS does not aim at preserving a hyaline cartilage layer but rather promotes the formation of a fibrin clot subsequently becoming fibrocartilage or cartilage/collagen type I, which may then decrease in quality over time, resulting in osteoarthritic changes [70, 88, 89]. Moreover, research indicates that deterioration of the natural congruency of the ankle joint occurs as cartilage type I demonstrates inferior wear characteristics in comparison with hyaline cartilage (cartilage/collagen type II) being associated with the degradation of a repaired articular surface $[74,98,111]$. However, long-term studies have not yet confirmed this [37, 123]. A clear correlation between inferior clinical outcomes and follow-up duration concerning the included studies in this review was not observed either, possibly due to the fact that it was not possible to gather data on mean follow-up durations from all included studies. Concerning pre-operative size and clinical outcome after BMS, a study from Choi et al. [25] including 120 primary ankles indicated that there is a definite cut-off point, that is, $1.5 \mathrm{~cm}^{2}$, as a prognostic influence on the risk of clinical failure. A more recent study by Ramponi et al. [99] shows that the cutoff point might be lower, around the size of $107 \mathrm{~mm}^{2}$. In our review, the range of the means of the reported pre-operative size for the BMS studies was 1.0 to $1.7 \mathrm{~cm}^{2}$ suggesting that BMS is indeed administered for smaller primary defects. The reported success rates of BMS therefore suggest that BMS could be regarded as a fair treatment strategy for the smaller primary defects.

As an alternative to BMS, a number of treatment options have focused on preserving hyaline cartilage and treating larger defects. The consensus that most of these interventions are considered as suitable treatment options when primary surgery to the OCDs has failed explains why there was a relatively lower number of patients included in these particular treatment groups. Furthermore, a number of publications on the osteochondral autograft system had to be excluded. Studies by Hangody et al. [50] and Fraser et al. [38] have yielded promising results, but were excluded as legal cases needed to be reopened for data provision.

Interestingly, only one study described the results of non-operative treatment implying that since 1996 studies have focused on developing novel surgical treatment options [109]. Likely, this is due to the poor success rates of non-operative treatments reported before 1996 [16, 102]. Although only twenty-six conservatively treated ankles were included in our review-with a success percentage of $62 \%$ [CI $43-78 \%$ ] - it is still recommended that initial treatment of symptomatic OCDs should consistently commence with a conservative protocol.

The AOFAS score was the most frequently used clinical score among the included studies. Sierevelt et al. [110] indicated that there are some concerns regarding this outcome score. A significant part of the 100 points depends on patient subjective outcomes introducing bias to the interpretation of the calculated success rates, as a high-level athlete would subjectively rate his or her surgery more critically than the average patient included in our systematic review. Moreover, the AOFAS score is not officially validated 
for the clinical evaluation of the treatment of talar OCDs. Therefore, future research should focus on developing a fortalar-OCD-validated outcome scale, in order to increase the homogeneity and uniformity in outcome assessment.

As the review shows that in $71 \%$ of the cases a history of ankle trauma was reported, it is as important to focus on prevention strategies as focusing on effective surgical treatment measures. Progression has been made regarding the development of cost-effective prevention programs for lateral and medial ankle sprains, for example by Verhagen [127] through the development of a mobile application system.

Furthermore, the analysis concerning methodological quality showed that a high number of studies included were of low methodological quality, except for two included RCTs [33, 100]. This underlines that the necessity for more sufficiently powered randomised studies is of paramount importance. Future research should therefore focus on conducting more randomised comparative clinical trials with uniform methodology and extended follow-up times. BMS should be compared to newly developed promising treatment options that focus on preserving hyaline cartilage and preventing the development of additional clinical complaints, such as donor-site morbidities observed in patients undergoing an OATS procedure. A possible future direction for such a promising treatment strategy is the internal fixation surgeries. In small patient series, these have been shown to induce a significant clinical improvement, possibly because these aim at preserving hyaline cartilage $[56,58]$.

There were a number of limitations concerning the present review. Firstly, the low quality of the included studies and the substantial heterogeneity regarding methodology account as major limitations. Additionally, separate success rates were calculated based on different scoring systems, as the AOFAS score was not always available for statistical analysis. Due to this, it was not possible to perform the conventional measure of summarising estimates of effectiveness. Concerning patient characteristics there was heterogeneity observed in the patient population. It was not possible to collect data concerning mean followup duration on all studies included, as these were not provided in all cases. Another limitation of the study is that it was not possible to perform a formal meta-analysis utilising mixed-effects logistics regression in order to compare between treatment groups. Regarding the BMS group and the studies within the osteo(chondral) transplantation group, those publications that had utilised a retrospective case series setting were pooled. This implies that the evidence retrieved from this simplified pooling method is based on lower level of evidence and may therefore contain methodological bias indicating that the pooled calculated success rates should not be used for decision of a particular treatment technique for talar OCDs, but merely be applied to inform patients in the process of explaining the expected success percentages of a particular treatment strategy. Moreover, the pooled success rate of the osteo(chondral) transplantation group combined studies reporting the effects of OATS procedures and an osteoperiosteal cylinder procedure possibly introducing some form of heterogeneity in this group as the type of grafts inserted in the OATS group was slightly different from the ones in the osteoperiosteal cylinder group [3, 40, 53, 54, 63, 64, 132]. The strengths of the present review are the inclusion of solely primary lesions, the thorough reference selection and the quality assessment of the included studies. Another major strength is the extensive corresponding author contact protocol regarding additional data retrieval and further clarification on methodology of included studies.

The clinical relevance of the present systematic review is that the separate and pooled success rates for the different surgical and non-surgical management options can be utilised to inform patients about the expected success percentages when undergoing treatment for primary talar osteochondral defects, which will facilitate the shared decision-making process between patients and physicians.

\section{Conclusions}

In conclusion, the present systematic review shows that none of the interventions for the treatment of primary osteochondral defects to the talus showed clinical superiority over another or others. A simplified pooling method for eleven retrospective case series in the BMS group yielded a success rate of $82 \%$ [CI 78-86\%], and for the seven combined OATS and osteoperiosteal cylinder graft studies the pooled success rate was calculated to be $77 \%$ [CI 66-85\%]. A high number of studies with low methodological quality were included, and heterogeneity in methodological nature of the studies and variety in reported success rates was observed. As a consequence, future research should focus on conducting sufficiently powered prospective investigations in a randomised comparative clinical trial setting using outcome scores validated for the treatment of talar OCDs.

Acknowledgements The authors would like to thank AMC's clinical librarian, F.S. van Etten-Jamaludin, for her work in the present systematic review. Additionally, the authors wish to thank all (corresponding) authors for having cooperated in the additional data retrieval process. Dr. W.A. van Enst and AMC's clinical statistician, Dr. R. Holman, should be thanked for their helpful comments with regard to conducting a systematic review according to the established guidelines. Also, E. R. de Jong and M. Gerritsen should be acknowledged for their statistical support.

Author's contributions JD and KL both contributed to the conception, design and data collection of the study, performed the analysis 
and interpretation of all data and wrote the manuscript. MR, CvB, SS and GK contributed to the conception and the design of the review and contributed to the data collection and analysis of the study. MR, $\mathrm{CvB}$, SS and GK also performed a third-party adjudication process and contributed to the writing of the manuscript. All authors read and approved the final manuscript.

\section{Compliance with ethical standards}

Conflict of interest The authors declare that they have no conflict of interest.

Funding There is no funding source.

Ethical approval This article does not contain any studies with human participants or animals performed by any of the authors.

Informed consent Informed consent is not required for review articles.

Open Access This article is distributed under the terms of the Creative Commons Attribution 4.0 International License (http://creativecommons.org/licenses/by/4.0/), which permits unrestricted use, distribution, and reproduction in any medium, provided you give appropriate credit to the original author(s) and the source, provide a link to the Creative Commons license, and indicate if changes were made.

\section{Appendix 1}

Full electronic search strategy used in this systematic review

\section{PubMed}

\begin{tabular}{|c|c|c|}
\hline \# & Searches & Results \\
\hline 1 & $\begin{array}{l}\text { "Osteochondritis } \\
\text { Dissecans"[Mesh] }\end{array}$ & \multirow{8}{*}{$\begin{array}{l}\text { Total number of results } \\
\text { 1996-2017: } 1053 \\
\text { hits }\end{array}$} \\
\hline 2 & $\begin{array}{l}\text { Osteochondritis dissecans[tiab] } \\
\text { OR osteochondro- } \\
\text { sis dissecans[tiab] OR } \\
\text { osteochondrolysis[tiab] OR } \\
\text { OCD[tiab] OR OLT[tiab] }\end{array}$ & \\
\hline 3 & $\begin{array}{l}\text { (osteochondral[tiab] } \\
\text { OR chondral[tiab] OR } \\
\text { transchondral[tiab] OR } \\
\text { cartilage } *[\text { tiab]) AND } \\
\text { (defect*[tiab] OR lesion*[tiab]) }\end{array}$ & \\
\hline 4 & \#1 OR \#2 OR \#3 & \\
\hline 5 & "Talus"[Mesh] & \\
\hline 6 & $\begin{array}{l}\text { talus[tiab] OR talar*[tiab] OR } \\
\text { ankle[tiab] }\end{array}$ & \\
\hline 7 & \#5 OR \#6 & \\
\hline 8 & \#4 AND \#7 & \\
\hline
\end{tabular}

\section{EMBASE (OVID)}

\begin{tabular}{lll}
\hline$\#$ & Searches & Results \\
\hline 1 & $\begin{array}{l}\text { (osteochondritis dissecans/or (osteochondritis } \\
\text { dissecans or osteochondrosis dissecans or }\end{array}$ & 1475 \\
& osteochondrolysis or OCD or OLT).ti,ab,kw. or \\
& $(($ osteochondral or chondral or osteochondral \\
& or transchondral or cartilage*) adj3 (defect* or \\
& lesion*)).ti,ab,kw.) and (talus/or (talus or talar* \\
& or ankle).ti,ab,kw.) & 1220 \\
\multicolumn{3}{c}{ limit 1 to yr = "1996-2017" }
\end{tabular}

\section{COCHRANE LIBRARY}

\begin{tabular}{|c|c|c|}
\hline$\#$ & Searches & Results \\
\hline 1 & $\begin{array}{l}\text { MeSH descriptor: [Osteochondritis Dissecans] } \\
\text { explode all trees }\end{array}$ & 8 \\
\hline 2 & $\begin{array}{l}\text { osteochondritis dissecans or osteochondrosis } \\
\text { dissecans or osteochondrolysis or OCD or } \\
\text { OLT:ti,ab,kw (Word variations have been } \\
\text { searched) }\end{array}$ & 1188 \\
\hline 3 & $\begin{array}{l}\text { (osteochondral or chondral or transchondral or } \\
\text { cartilage*) and (defect* or lesion*):ti,ab,kw } \\
\text { (Word variations have been searched) }\end{array}$ & 343 \\
\hline 4 & $\# 1$ or $\# 2$ or $\# 3$ & 1516 \\
\hline 5 & MeSH descriptor: [Talus] explode all trees & 33 \\
\hline 6 & $\begin{array}{l}\text { talus or talar* or ankle:ti,ab,kw (Word variations } \\
\text { have been searched) }\end{array}$ & 5266 \\
\hline 7 & \#5 or \#6 & 5266 \\
\hline 8 & $\begin{array}{l}\text { \#4 and \#7, Publication Year from } 1996 \text { to 2017, } \\
\text { in Cochrane Reviews (Reviews and Protocols), } \\
\text { Other Reviews and Trials }\end{array}$ & 33 \\
\hline
\end{tabular}

\section{Appendix 2}

Grading scale as proposed by Thompson and Loomer [118]

\begin{tabular}{lllll}
\hline Rating & Pain & Function & Examination X-ray \\
\hline Good & None & $\begin{array}{c}\text { No restrictionNormal } \\
\text { on activities }\end{array}$ & Normal \\
Fair & $\begin{array}{c}\text { Occasion- } \\
\text { ally with } \\
\text { activity }\end{array}$ & $\begin{array}{c}\text { Some limita- } \\
\text { tion of } \\
\text { activities }\end{array}$ & $\begin{array}{l}\text { Mild swell- } \\
\text { decrease in } \\
\text { motion }\end{array}$ & $\begin{array}{c}\text { Minimal } \\
\text { change }\end{array}$ \\
Poor & $\begin{array}{c}\text { As before or } \\
\text { worse }\end{array}$ & $\begin{array}{c}\text { Moderate } \\
\text { restriction } \\
\text { of activities }\end{array}$ & $\begin{array}{l}\text { Arthrosis, i.e. Degenerative } \\
\text { increased } \\
\text { swelling } \\
\text { change }\end{array}$ \\
& & and crepitus \\
\hline
\end{tabular}




\section{Appendix 3}

Quality assessment scale utilized

\section{Newcastle - Ottawa quality assessment scale Non-randomized studies adjusted for case series}

Note: A study can be awarded a maximum of one star for each numbered item within the Selection and Outcome categories.

\section{Study Design}

1. Type of Study
a. Prospective*
b. Retrospective
c. Other
d. Not described

2. Set-up
a. According to protocol*
b. Without protocol
c. No protocol described

\section{Selection}

3. Representativeness of the exposed cohort
a. Truly representative of the average talar osteochondral defect patient in the community*
b. Somewhat representative of the average talar osteochondral defect patient in the community*
c. Selected group of patients by orthopaedic surgeon
d. No description of the derivation of the cohort

\section{Outcome}

4. Assessment of outcome
a. Independent blind assessment*
b. Record linkage*
c. Self-report
d. No description

5. Adequacy of follow-up of series
a. Complete follow-up - all patients accounted for*
b. Subjects lost to follow-up unlikely to introduce bias - small number lost $(<5 \%)^{*}$
c. Follow-up rate $<95 \%$ and no description of those lost
d. No statement

Number of assigned stars

\begin{tabular}{l}
\hline Study (title, author, year) Study design $\quad$ Selection \\
\hline \\
Each included study was graded on methodological quality by two independent reviewers utilizing \\
adjusted version of the Newcastle Ottawa Scale which is included above. Categories of study design, \\
selection of patients, and outcome were scored by means of a scoring system using quantitive \\
amounts of stars, and respectively for each category a maximum of 2 stars 1 star, and 2 stars could \\
be obtained (maximum is 5 stars).
\end{tabular}




\section{References}

1. Aaron RK, Wang S, Ciombor DM (2002) Upregulation of basal TGFbeta1 levels by EMF coincident with chondrogenesisimplications for skeletal repair and tissue engineering. J Orthop Res 20:233-240

2. Ahmad J, Jones K (2016) Comparison of osteochondral autografts and allografts for treatment of recurrent or large talar osteochondral lesions. Foot Ankle Int 37:40-50

3. Al-Shaikh RA, Chou LB, Mann JA, Dreeben SM, Prieskorn D (2002) Autologous osteochondral grafting for talar cartilage defects. Foot Ankle Int 23:381-389

4. Anders S, Goetz J, Schubert T, Grifka J, Schaumburger J (2012) Treatment of deep articular talus lesions by matrix associated autologous chondrocyte implantation - results at five years. Int Orthop 36:2279-2285

5. Anders S, Lechler P, Rackl W, Grifka J, Schaumburger J (2012) Fluoroscopy-guided retrograde core drilling and cancellous bone grafting in osteochondral defects of the talus. Int Orthop 36:1635-1640

6. Anderson IF, Crichton KJ, Grattan-Smith T, Cooper RA, Brazier D (1989) Osteochondral fractures of the dome of the talus. J Bone Jt Surg Am 71:1143-1152

7. Arauz JMY, Vecchio JJD, Bilbao F, Raimondi N (2016) Osteochondral lesions of the talus treatment with fresh frozen allograft. Foot Ankle Surg. doi:10.1016/j.fas.2016.1009.1002

8. Baker CL Jr, Morales RW (1999) Arthroscopic treatment of transchondral talar dome fractures: a long-term follow-up study. Arthroscopy 15:197-202

9. Baldini A, Anderson JA, Zampetti P, Pavlov H, Sculco TP (2006) A new patellofemoral scoring system for total knee arthroplasty. Clin Orthop Relat Res 452:150-154

10. Bandi W (1977) Operative treatment of chondromalacia patellae. Zentralbl Chir 102:1297-1301

11. Becher C, Thermann H (2005) Results of microfracture in the treatment of articular cartilage defects of the talus. Foot Ankle Int 26:583-589

12. Beck S, Classen T, Haversath M, Jager M, Landgraeber S (2016) Operative technique and clinical outcome in endoscopic core decompression of osteochondral lesions of the talus: a pilot study. Med Sci Monit 22:2278-2283

13. Benthien JP, Behrens P (2010) Autologous matrix-induced chondrogenesis (AMIC). A one-step procedure for retropatellar articular resurfacing. Acta Orthop Belg 76:260-263

14. Benthien JP, Behrens P (2010) Autologous matrix-induced chondrogenesis (AMIC): combining microfracturing and a collagen I/III matrix for articular cartilage resurfacing. Cartilage 1:65-68

15. Berndt AL, Harty M (1959) Transchondral fractures (osteochondritis dissecans) of the talus. J Bone Jt Surg Am 41:988-1020

16. Blom JM, Strijk SP (1975) Lesions of the trochlea tali. Osteochondral fractures and osteochondritis dissecans of the trochlea tali. Radiol Clin 44:387-396

17. Boyle DL, Moore J, Yang L, Sorkin LS, Firestein GS (2002) Spinal adenosine receptor activation inhibits inflammation and joint destruction in rat adjuvant-induced arthritis. Arthritis Rheum 46:3076-3082

18. Brittberg M, Winalski CS (2003) Evaluation of cartilage injuries and repair. J Bone Jt Surg Am 85(Suppl II):58-69

19. Brown LD, Cai TT, DasGupta A (2001) Interval estimation for a binomial proportion. Stat Sci 16:101-133

20. Canady JW, Zeitler DP, Thompson SA, Nicholas CD (1993) Suitability of the iliac crest as a site for harvest of autogenous bone grafts. Cleft Palate Craniofac J 30:579-581
21. Carlsson AM (1983) Assessment of chronic pain. I. Aspects of the reliability and validity of the visual analogue scale. Pain 16:87-101

22. Chen W, Tang K, Yuan C, Zhou Y, Tao X (2015) Intermediate results of large cystic medial osteochondral lesions of the talus treated with osteoperiosteal cylinder autografts from the medial tibia. Arthroscopy 31:1557-1564

23. Chien PF, Khan KS, Siassakos D (2012) Registration of systematic reviews: PROSPERO. BJOG 119:903-905

24. Choi JI, Lee KB (2015) Comparison of clinical outcomes between arthroscopic subchondral drilling and microfracture for osteochondral lesions of the talus. Knee Surg Sports Traumatol Arthrosc 24:2140-2147

25. Choi WJ, Park KK, Kim BS, Lee JW (2009) Osteochondral lesion of the talus: is there a critical defect size for poor outcome? Am J Sports Med 37:1974-1980

26. Cohen SB, Gill SS, Baer GS, Leo BM, Scheld WM, Diduch DR (2004) Reducing joint destruction due to septic arthrosis using an adenosine2A receptor agonist. J Orthop Res 22:427-435

27. Cuttica DJ, Smith WB, Hyer CF, Philbin TM, Berlet GC (2011) Osteochondral lesions of the talus: predictors of clinical outcome. Foot Ankle Int 32:1045-1051

28. D’Ambrosi R, Maccario C, Serra N, Liuni F, Usuelli FG (2016) Osteochondral lesions of the talus and autologous matrixinduced chondrogenesis: is age a negative predictor outcome? Arthroscopy 33:428-435

29. de l'Escalopier N, Barbier O, Mainard D, Mayer J, Ollat D, Versier G (2015) Outcomes of talar dome osteochondral defect repair using osteocartilaginous autografts: 37 cases of Mosaicplasty(R). Orthop Traumatol Surg Res 101:97-102

30. Dipaola JD, Nelson DW, Colville MR (1991) Characterizing osteochondral lesions by magnetic resonance imaging. Arthroscopy 7:101-104

31. Domayer SE, Welsch GH, Stelzeneder D, Hirschfeld C, Quirbach S, Nehrer S, Dorotka R, Mamisch TC, Trattnig S (2011) Microfracture in the ankle: clinical results and MRI with T2-mapping at 3.0 $\mathrm{T}$ after 1 to 8 years. Cartilage 2:73-80

32. Donnenwerth MP, Roukis TS (2012) Outcome of arthroscopic debridement and microfracture as the primary treatment for osteochondral lesions of the talar dome. Arthroscopy 28:1902-1907

33. Doral MN, Bilge O, Batmaz G, Donmez G, Turhan E, Demirel M, Atay OA, Uzumcugil A, Atesok K, Kaya D (2012) Treatment of osteochondral lesions of the talus with microfracture technique and postoperative hyaluronan injection. Knee Surg Sports Traumatol Arthrosc 20:1398-1403

34. Doré JL, Besson J, Fourastier J, Marcillaud G, Rosset P, Mabit C, Watin-Augouard L, Franck A, Rogez J (1995) Lésions ostéochondrales du dome astragalien. Ann Orthop Ouest 27:143-194

35. Dorotka R, Kotz R, Trattnig S, Nehrer S (2004) Mid-term results of autologous chondrocyte transplantation in knee and ankle. A one- to six-year follow-up study. Z Rheumatol 63:385-392

36. El-Rashidy H, Villacis D, Omar I, Kelikian AS (2011) Fresh osteochondral allograft for the treatment of cartilage defects of the talus: a retrospective review. J Bone Jt Surg Am 93:1634-1640

37. Ferkel RD, Zanotti RM, Komenda GA, Sgaglione NA, Cheng MS, Applegate GR, Dopirak RM (2008) Arthroscopic treatment of chronic osteochondral lesions of the talus: long-term results. Am J Sports Med 36:1750-1762

38. Fraser EJ, Harris MC, Prado MP, Kennedy JG (2016) Autologous osteochondral transplantation for osteochondral lesions of the talus in an athletic population. Knee Surg Sports Traumatol Arthrosc 24:1272-1279 
39. Gagliese L, Weizblit N, Ellis W, Chan VW (2005) The measurement of postoperative pain: a comparison of intensity scales in younger and older surgical patients. Pain 117:412-420

40. Gautier E, Kolker D, Jakob RP (2002) Treatment of cartilage defects of the talus by autologous osteochondral grafts. J Bone Jt Surg Br 84:237-244

41. Geerling J, Zech S, Kendoff D, Citak M, O'Loughlin PF, Hufner T, Krettek C, Richter M (2009) Initial outcomes of 3-dimensional imaging-based computer-assisted retrograde drilling of talar osteochondral lesions. Am J Sports Med 37:1351-1357

42. Giannini S, Buda R, Faldini C, Vannini F, Bevoni R, Grandi G, Grigolo B, Berti L (2005) Surgical treatment of osteochondral lesions of the talus in young active patients. J Bone Jt Surg Am 87(Suppl II):28-41

43. Giannini S, Buda R, Vannini F, Di Caprio F, Grigolo B (2008) Arthroscopic autologous chondrocyte implantation in osteochondral lesions of the talus: surgical technique and results. Am J Sports Med 36:873-880

44. Giannini S, Buda R, Ruffilli A, Cavallo M, Pagliazzi G, Bulzamini MC, Desando G, Luciani D, Vannini F (2014) Arthroscopic autologous chondrocyte implantation in the ankle joint. Knee Surg Sports Traumatol Arthrosc 22:1311-1319

45. Goh GS, Bin Abd Razak HR, Mitra AK (2015) Outcomes are favorable after arthroscopic treatment of osteochondritis dissecans of the talus. J Foot Ankle Surg 54:57-60

46. Guhl JF (1982) Arthroscopic treatment of osteochondritis dissecans. Clin Orthop Relat Res 167:65-74

47. Gul M, Cetinkaya E, Aykut US, Ozkul B, Saygili MS, Akman YE, Kabukcuoglu YS (2016) Effect of the presence of subchondral cysts on treatment results of autologous osteochondral graft transfer in osteochondral lesions of the talus. J Foot Ankle Surg 55:1003-1006

48. Halasi T, Kynsburg A, Tallay A, Berkes I (2004) Development of a new activity score for the evaluation of ankle instability. Am J Sports Med 32:899-908

49. Hale SA, Hertel J (2005) Reliability and sensitivity of the foot and ankle disability index in subjects with chronic ankle instability. J Athl Train 40:35-40

50. Hangody L, Vasarhelyi G, Hangody LR, Sukosd Z, Tibay G, Bartha L, Bodo G (2008) Autologous osteochondral graftingtechnique and long-term results. Injury 39(Suppl):32-39

51. Hefti F, Muller W, Jakob RP, Staubli HU (1993) Evaluation of knee ligament injuries with the IKDC form. Knee Surg Sports Traumatol Arthrosc 1:226-234

52. Hepple S, Winson IG, Glew D (1999) Osteochondral lesions of the talus: a revised classification. Foot Ankle Int 20:789-793

53. Hu Y, Guo Q, Jiao C, Mei Y, Jiang D, Wang J, Zheng Z (2013) Treatment of large cystic medial osteochondral lesions of the talus with autologous osteoperiosteal cylinder grafts. Arthroscopy 29:1372-1379

54. Imhoff AB, Paul J, Ottinger B, Wortler K, Lammle L, Spang J, Hinterwimmer S (2011) Osteochondral transplantation of the talus: long-term clinical and magnetic resonance imaging evaluation. Am J Sports Med 39:1487-1493

55. Jung HG, Carag JA, Park JY, Kim TH, Moon SG (2011) Role of arthroscopic microfracture for cystic type osteochondral lesions of the talus with radiographic enhanced MRI support. Knee Surg Sports Traumatol Arthrosc 19:858-862

56. Kerkhoffs GM, Reilingh ML, Gerards RM, de Leeuw PA (2016) Lift, drill, fill and fix (LDFF): a new arthroscopic treatment for talar osteochondral defects. Knee Surg Sports Traumatol Arthrosc 24:1265-1271

57. Kilic A, Kabukcuoglu Y, Gul M, Ozkaya U, Sokucu S (2009) Early results of open mosaicplasty in osteochondral lesions of the talus. Acta Orthop Traumatol Turc 43:235-242
58. Kim HN, Kim GL, Park JY, Woo KJ, Park YW (2013) Fixation of a posteromedial osteochondral lesion of the talus using a three-portal posterior arthroscopic technique. J Foot Ankle Surg 52:402-405

59. Kitaoka HB, Alexander IJ, Adelaar RS, Nunley JA, Myerson MS, Sanders M (1994) Clinical rating systems for the anklehindfoot, midfoot, hallux, and lesser toes. Foot Ankle Int 15:349-353

60. Kubosch EJ, Erdle B, Izadpanah K, Kubosch D, Uhl M, Sudkamp NP, Niemeyer P (2016) Clinical outcome and T2 assessment following autologous matrix-induced chondrogenesis in osteochondral lesions of the talus. Int Orthop 40:65-71

61. Kuni B, Schmitt H, Chloridis D, Ludwig K (2012) Clinical and MRI results after microfracture of osteochondral lesions of the talus. Arch Orthop Trauma Surg 132:1765-1771

62. Lahm A, Erggelet C, Steinwachs M, Reichelt A (2000) Arthroscopic management of osteochondral lesions of the talus: results of drilling and usefulness of magnetic resonance imaging before and after treatment. Arthroscopy 16:299-304

63. Largey A, Faure P, Hebrard W, Hamoui M, Canovas F (2009) Osteochondral transfer using a transmalleolar approach for arthroscopic management of talus posteromedial lesions. Orthop Traumatol Surg Res 95:537-542

64. Lee CH, Chao KH, Huang GS, Wu SS (2003) Osteochondral autografts for osteochondritis dissecans of the talus. Foot Ankle Int 24:815-822

65. Lee KB, Park HW, Cho HJ, Seon JK (2015) Comparison of arthroscopic microfracture for osteochondral lesions of the talus with and without subchondral cyst. Am J Sports Med 43:1951-1956

66. Lee KT, Kim JS, Young KW, Lee YK, Park YU, Kim YH, Cho HK (2013) The use of fibrin matrix-mixed gel-type autologous chondrocyte implantation in the treatment for osteochondral lesions of the talus. Knee Surg Sports Traumatol Arthrosc 21:1251-1260

67. Liberati A, Altman DG, Tetzlaff J, Mulrow C, Gøtzsche PC, Ioannidis JPA, Clarke M, Devereaux PJ, Kleijnen J, Moher D (2009) The PRISMA statement for reporting systematic reviews and meta-analyses of studies that evaluate healthcare interventions: explanation and elaboration. BMJ 339:b2700

68. Loomer R, Fisher C, Lloyd-Smith R, Sisler J, Cooney T (1993) Osteochondral lesions of the talus. Am J Sports Med 21:13-19

69. Loveday D, Clifton R, Robinson A (2010) Interventions for treating osteochondral defects of the talus in adults. Cochrane Database Syst Rev. doi:10.1002/14651858.CD008104.pub2

70. Lynn AK, Brooks RA, Bonfield W, Rushton N (2004) Repair of defects in articular joints. Prospects for materialbased solutions in tissue engineering. $\mathrm{J}$ Bone $\mathrm{Jt}$ Surg $\mathrm{Br}$ 86:1093-1099

71. Lysholm J, Gillquist J (1982) Evaluation of knee ligament surgery results with special emphasis on use of a scoring scale. Am J Sports Med 10:150-154

72. Mandelbaum BR, Browne JE, Fu F, Micheli L, Mosely JB Jr, Erggelet C, Minas T, Peterson L (1998) Articular cartilage lesions of the knee. Am J Sports Med 26:853-861

73. Marlovits S, Singer P, Zeller P, Mandl I, Haller J, Trattnig S (2006) Magnetic resonance observation of cartilage repair tissue (MOCART) for the evaluation of autologous chondrocyte transplantation: determination of interobserver variability and correlation to clinical outcome after 2 years. Eur J Radiol 57:16-23

74. Marsh JL, Buckwalter J, Gelberman R, Dirschl D, Olson S, Brown T, Llinias A (2002) Articular fractures: does an anatomic reduction really change the result? J Bone Jt Surg Am 84:1259-1271 
75. Martin RL, Irrgang JJ, Burdett RG, Conti SF, Van Swearingen JM (2005) Evidence of validity for the foot and ankle ability measure (FAAM). Foot Ankle Int 26:968-983

76. McCullough CJ, Venugopal V (1979) Osteochondritis dissecans of the talus: the natural history. Clin Orthop Relat Res 144:264-268

77. Mendicino RW, Lee MS, Grossman JP, Shromoff PJ (1998) Oblique medial malleolar osteotomy for the management of talar dome lesions. J Foot Ankle Surg 37:516-523

78. Ming SH, Tay Keng Jin D, Amit Kanta M (2004) Arthroscopic treatment of osteochondritis dissecans of the talus. Foot Ankle Surg 10:181-186

79. Mintz DN, Tashjian GS, Connell DA, Deland JT, O'Malley M, Potter HG (2003) Osteochondral lesions of the talus: a new magnetic resonance grading system with arthroscopic correlation. Arthroscopy 19:353-359

80. Mitchell ME, Giza E, Sullivan MR (2009) Cartilage transplantation techniques for talar cartilage lesions. J Am Acad Orthop Surg 17:407-414

81. Mongkhon JM, Thach M, Shi Q, Fernandes JC, Fahmi H, Benderdour M (2014) Sorbitol-modified hyaluronic acid reduces oxidative stress, apoptosis and mediators of inflammation and catabolism in human osteoarthritic chondrocytes. Inflamm Res 63:691-701

82. Musculoskeletal outcomes data evaluation and management system (MODEMS): AAOS outcome questionnaire. http:// www.aaos.org. Accessed 22 May 2016

83. Naal FD, Impellizzeri FM, Huber M, Rippstein PF (2008) Cross-cultural adaptation and validation of the Foot Function Index for use in German-speaking patients with foot complaints. Foot Ankle Int 29:1222-1228

84. Nehrer S, Domayer SE, Hirschfeld C, Stelzeneder D, Trattnig S, Dorotka R (2011) Matrix-associated and autologous chondrocyte transplantation in the ankle: clinical and MRI follow-up after 2 to 11 years. Cartilage 2:81-91

85. Niemeyer P, Salzmann G, Schmal H, Mayr H, Sudkamp NP (2012) Autologous chondrocyte implantation for the treatment of chondral and osteochondral defects of the talus: a metaanalysis of available evidence. Knee Surg Sports Traumatol Arthrosc 20:1696-1703

86. Noyes FR, Barber SD, Mooar LA (1989) A rationale for assessing sports activity levels and limitations in knee disorders. Clin Orthop Relat Res 246:238-249

87. Noyes FR, Stabler CL (1989) A system for grading articular cartilage lesions at arthroscopy. Am J Sports Med 17:505-513

88. O'Driscoll SW (1998) The healing and regeneration of articular cartilage. J Bone Jt Surg Am 80:1795-1812

89. O'Loughlin PF, Heyworth BE, Kennedy JG (2010) Current concepts in the diagnosis and treatment of osteochondral lesions of the ankle. Am J Sports Med 38:392-404

90. Ogilvie-Harris DJ, Mahomed N, Demaziere A (1993) Anterior impingement of the ankle treated by arthroscopic removal of bony spurs. J Bone Jt Surg Br 75:437-440

91. Ongaro A, Pellati A, Masieri FF, Caruso A, Setti S, Cadossi R, Biscione R, Massari L, Fini M, De Mattei M (2011) Chondroprotective effects of pulsed electromagnetic fields on human cartilage explants. Bioelectromagnetics 32:543-551

92. Orr JD, Dunn JC, Heida KA Jr, Kusnezov NA, Waterman BR, Belmont PJ Jr (2017) Results and functional outcomes of structural fresh osteochondral allograft transfer for treatment of osteochondral lesions of the talus in a highly active population. Foot Ankle Spec 10:125-132

93. Pardiwala D, Bhayde SR, Maheshwari M, Gupta K, Siddiqui W (2013) Autologous chondrocyte implantation versus bone marrow stimulation for talar osteochondral defects: a comparative study of clinical outcomes, mocart score, and T2 cartilage mapping. Arthroscopy 29(Suppl):e180-e181
94. Park HW, Lee KB (2015) Comparison of chondral versus osteochondral lesions of the talus after arthroscopic microfracture. Knee Surg Sports Traumatol Arthrosc 23:860-867

95. Petersen W, Taheri P, Schliemann B, Achtnich A, Winter C, Forkel P (2014) Osteochondral transplantation for the treatment of osteochondral defects at the talus with the Diamond twin system $((\mathrm{R}))$ and graft harvesting from the posterior femoral condyles. Arch Orthop Trauma Surg 134:843-852

96. Polat G, Ersen A, Erdil ME, Kizilkurt T, Kilicoglu O, Asik M (2016) Long-term results of microfracture in the treatment of talus osteochondral lesions. Knee Surg Sports Traumatol Arthrosc 24:1299-1303

97. Pritsch M, Horoshovski H, Farine I (1986) Arthroscopic treatment of osteochondral lesions of the talus. J Bone Jt Surg Am 68:862-865

98. Qiu YS, Shahgaldi BF, Revell WJ, Heatley FW (2003) Observations of subchondral plate advancement during osteochondral repair: a histomorphometric and mechanical study in the rabbit femoral condyle. Osteoarthritis Cartilage 11:810-820

99. Ramponi L, Yasui Y, Murawski CD, Ferkel RD, DiGiovanni CW, Kerkhoffs GM, Calder JD, Takao M, Vannini F, Choi WJ, Lee JW, Stone J, Kennedy JG (2016) Lesion size is a predictor of clinical outcomes after bone marrow stimulation for osteochondral lesions of the talus: a systematic review. Am J Sports Med 45:1698-1705

100. Reilingh ML, van Bergen CJ, Gerards RM, van Eekeren IC, de Haan RJ, Sierevelt IN, Kerkhoffs GM, Krips R, Meuffels DE, van Dijk CN, Blankevoort L (2016) Effects of pulsed electromagnetic fields on return to sports after arthroscopic debridement and microfracture of osteochondral talar defects: a randomized, double-blind, placebo-controlled, multicenter trial. Am J Sports Med 44:1292-1300

101. Robinson DE, Winson IG, Harries WJ, Kelly AJ (2003) Arthroscopic treatment of osteochondral lesions of the talus. J Bone Jt Surg Br 85:989-993

102. Roden S, Tillegard P, Unanderscharin L (1953) Osteochondritis dissecans and similar lesions of the talus: report of fifty-five cases with special reference to etiology and treatment. Acta Orthop Scand 23:51-66

103. Sadoghi P, Leithner A, Dorotka R, Vavken P (2013) Effect of pulsed electromagnetic fields on the bioactivity of human osteoarthritic chondrocytes. Orthopedics 36:e360-e365

104. Sallakh SE (2012) Arthroscopic debridement and microfracture for osteochondral lesions of the talus. Curr Orthop Pract 23:116-121

105. Saxena A, Eakin C (2007) Articular talar injuries in athletes: results of microfracture and autogenous bone graft. Am J Sports Med 35:1680-1687

106. Scranton PE Jr, McDermott JE (2001) Treatment of type V osteochondral lesions of the talus with ipsilateral knee osteochondral autografts. Foot Ankle Int 22:380-384

107. Sefton GK, George J, Fitton JM, McMullen H (1979) Reconstruction of the anterior talofibular ligament for the treatment of the unstable ankle. J Bone Jt Surg Br 61:352-354

108. Shang XL, Tao HY, Chen SY, Li YX, Hua YH (2016) Clinical and MRI outcomes of HA injection following arthroscopic microfracture for osteochondral lesions of the talus. Knee Surg Sports Traumatol Arthrosc 24:1243-1249

109. Shearer C, Loomer R, Clement D (2002) Nonoperatively managed stage 5 osteochondral talar lesions. Foot Ankle Int 23:651-654

110. Sierevelt IN, van Bergen CJ, Silbernagel KN, Haverkamp D, Karlsson J (2014) Outcomes scores. In: van Dijk CN, Kennedy JG (eds) Talar osteochondral defects: diagnosis, planning, treatment and rehabilitation, vol 1. Springer, Heidelberg, pp 95-104

111. Stufkens SA, Knupp M, Horisberger M, Lampert C, Hintermann B (2010) Cartilage lesions and the development of 
osteoarthritis after internal fixation of ankle fractures: a prospective study. J Bone Jt Surg Am 92:279-286

112. Sun SF, Chou YJ, Hsu CW, Hwang CW, Hsu PT, Wang JL, Hsu YW, Chou MC (2006) Efficacy of intra-articular hyaluronic acid in patients with osteoarthritis of the ankle: a prospective study. Osteoarthritis Cartilage 14:867-874

113. Takakura Y, Tanaka Y, Kumai T, Tamai S (1995) Low tibial osteotomy for osteoarthritis of the ankle. Results of a new operation in 18 patients. J Bone Jt Surg Br 77:50-54

114. Takao M, Innami K, Komatsu F, Matsushita T (2010) Retrograde cancellous bone plug transplantation for the treatment of advanced osteochondral lesions with large subchondral lesions of the ankle. Am J Sports Med 38:1653-1660

115. Tao H, Shang X, Lu R, Li H, Hua Y, Feng X, Chen S (2014) Quantitative magnetic resonance imaging (MRI) evaluation of cartilage repair after microfracture (MF) treatment for adult unstable osteochondritis dissecans (OCD) in the ankle: correlations with clinical outcome. Eur Radiol 24:1758-1767

116. Tegner Y, Lysholm J (1985) Rating systems in the evaluation of knee ligament injuries. Clin Orthop Relat Res 198:43-49

117. Thermann H (1994) Treatment of osteochondritis dissecans of the talus: a long-term follow-up. Sports Med Arthrosc 2:284-288

118. Thompson JP, Loomer RL (1984) Osteochondral lesions of the talus in a sports medicine clinic. A new radiographic technique and surgical approach. Am J Sports Med 12:460-463

119. Tol JL, Struijs PA, Bossuyt PM, Verhagen RA, van Dijk CN (2000) Treatment strategies in osteochondral defects of the talar dome: a systematic review. Foot Ankle Int 21:119-126

120. Usuelli FG, Grassi M, Manzi L, Guarrella V, Boga M, de Girolamo L (2016) Treatment of osteochondral lesions of the talus with autologous collagen-induced chondrogenesis: clinical and magnetic resonance evaluation at one-year follow-up. Joints 4:80-86

121. Valderrabano V, Miska M, Leumann A, Wiewiorski M (2013) Reconstruction of osteochondral lesions of the talus with autologous spongiosa grafts and autologous matrix-induced chondrogenesis. Am J Sports Med 41:519-527

122. Valderrabano V, Barg A, Alattar A, Wiewiorski M (2014) Osteochondral lesions of the ankle joint in professional soccer players: treatment with autologous matrix-induced chondrogenesis. Foot Ankle Spec 7:522-528

123. van Bergen CJ, Kox LS, Maas M, Sierevelt IN, Kerkhoffs GM, van Dijk CN (2013) Arthroscopic treatment of osteochondral defects of the talus: outcomes at eight to twenty years of followup. J Bone Jt Surg Am 95:519-525

124. van Bergen CJ, van Eekeren IC, Reilingh ML, Sierevelt IN, van Dijk CN (2013) Treatment of osteochondral defects of the talus with a metal resurfacing inlay implant after failed previous surgery: a prospective study. Bone Jt J 95:1650-1655

125. van Dijk CN, Verhagen RA, Tol JL (1997) Arthroscopy for problems after ankle fracture. J Bone Jt Surg Br 79:280-284

126. van Dijk CN, van Bergen CJ (2008) Advancements in ankle arthroscopy. J Am Acad Orthop Surg 16:635-646

127. Verhagen E (2015) Ankle: avoid another ankle sprain! Br J Sports Med 49:1220

128. Verhagen RA, Struijs PA, Bossuyt PM, van Dijk CN (2003) Systematic review of treatment strategies for osteochondral defects of the talar dome. Foot Ankle Clin 8:233-242

129. Vincenzi F, Targa M, Corciulo C, Gessi S, Merighi S, Setti S, Cadossi R, Goldring MB, Borea PA, Varani K (2013) Pulsed electromagnetic fields increased the anti-inflammatory effect of $\mathrm{A}(2) \mathrm{A}$ and $\mathrm{A}(3)$ adenosine receptors in human T/C-28a2 chondrocytes and hFOB 1.19 osteoblasts. PLoS One. doi:10.1371/ journal.pone.0065561

130. Volpi P, Bait C, Quaglia A, Redaelli A, Prospero E, Cervellin M, Stanco D, de Girolamo L (2014) Autologous collageninduced chondrogenesis technique (ACIC) for the treatment of chondral lesions of the talus. Knee Surg Sports Traumatol Arthrosc 22:1320-1326

131. Ware JE Jr, Gandek B, Kosinski M, Aaronson NK, Apolone G, Brazier J, Bullinger M, Kaasa S, Leplege A, Prieto L, Sullivan M, Thunedborg K (1998) The equivalence of SF-36 summary health scores estimated using standard and country-specific algorithms in 10 countries: results from the IQOLA Project. International Quality of Life Assessment. J Clin Epidemiol 51:1167-1170

132. Woelfle JV, Reichel H, Nelitz M (2013) Indications and limitations of osteochondral autologous transplantation in osteochondritis dissecans of the talus. Knee Surg Sports Traumatol Arthrosc 21:1925-1930

133. Yoshimura I, Kanazawa K, Takeyama A, Angthong C, Ida T, Hagio T, Hanada H, Naito M (2013) Arthroscopic bone marrow stimulation techniques for osteochondral lesions of the talus: prognostic factors for small lesions. Am J Sports Med 41:528-534

134. Zengerink M, Szerb I, Hangody L, Dopirak RM, Ferkel RD, van Dijk CN (2006) Current concepts: treatment of osteochondral ankle defects. Foot Ankle Clin 11:331-359

135. Zengerink M, Struijs PA, Tol JL, van Dijk CN (2010) Treatment of osteochondral lesions of the talus: a systematic review. Knee Surg Sports Traumatol Arthrosc 18:238-246

136. Zhu Y, Xu X (2016) Osteochondral autograft transfer combined with cancellous allografts for large cystic osteochondral defect of the talus. Foot Ankle Int 37:1113-1118 